\title{
Navigating Between Stealth Advocacy and Unconscious Dogmatism: The Challenge of Researching the Norms, Politics and Power of Global Health
}

\author{
Gorik Ooms ${ }^{1,2^{*}}$
}

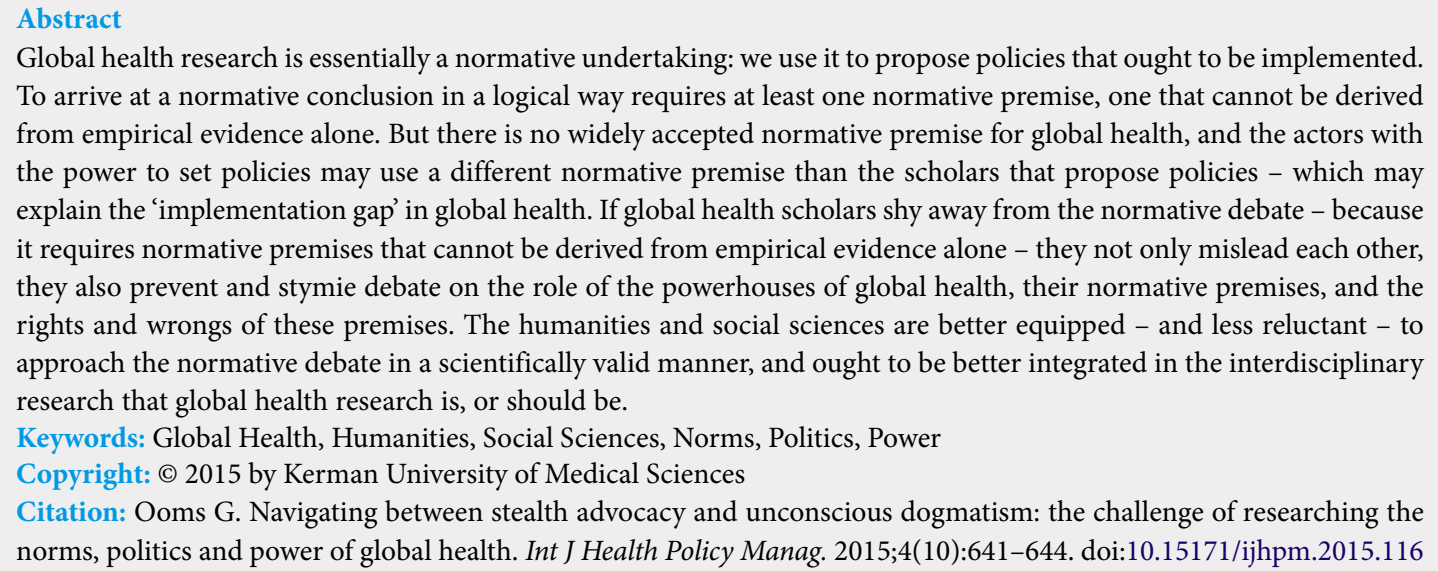

Global health research is essentially a normative undertaking: we use it to propose policies that ought to be implemented. To arrive at a normative conclusion in a logical way requires at least one normative premise, one that cannot be derived from empirical evidence alone. But there is no widely accepted normative premise for global health, and the actors with the power to set policies may use a different normative premise than the scholars that propose policies - which may explain the 'implementation gap' in global health. If global health scholars shy away from the normative debate - because it requires normative premises that cannot be derived from empirical evidence alone - they not only mislead each other, they also prevent and stymie debate on the role of the powerhouses of global health, their normative premises, and the rights and wrongs of these premises. The humanities and social sciences are better equipped - and less reluctant - to approach the normative debate in a scientifically valid manner, and ought to be better integrated in the interdisciplinary research that global health research is, or should be.

Keywords: Global Health, Humanities, Social Sciences, Norms, Politics, Power

Copyright: () 2015 by Kerman University of Medical Sciences

Citation: Ooms G. Navigating between stealth advocacy and unconscious dogmatism: the challenge of researching the norms, politics and power of global health. Int J Health Policy Manag. 2015;4(10):641-644. doi:10.15171/ijhpm.2015.116

\section{Article History:}

Received: 1 April 2015

Accepted: 14 June 2015

ePublished: 16 June 2015

*Correspondence to:

Gorik Ooms

Email: gooms@itg.be

\section{Introduction}

Several papers exploring the role of politics and power in global health have been published in this young journal recently ${ }^{1-13}$; which suggests that a new journal may have been needed to allow for this important discussion. In my opinion, this debate is vital for global health science-and I mean vital: I do not think the academic arm of global health can 'survive' in any meaningful way without addressing the role of norms, politics and power in global health head on. But I know that my position makes many of my colleagues nervous. As I will explain further below, it is not possible to discuss the politics of global health without discussing the normative premises behind the politics, and normative premises cannot be logically derived from empirical evidence alone. But if we step away from the purely empirical evidence-based approach to global health, ${ }^{14}$ will we not inevitably return to a form of global health research "driven by crises, hot issues, and the concerns of organized interest groups?"15 In my opinion, this is a false dilemma, as a purely empirical evidence-based approach to global health research is a fiction and thus aiming for it makes little sense. Worse, by denying that researchers, like all humans, have personal opinions, such an approach drives researchers' personal opinion underground, turning global health science into unconscious dogmatism or stealth advocacy, avoiding the crucial debate about the politics and underlying normative premises of global health.
Global Health Research Is Essentially Normative, but Lacks a Widely Accepted Normative Premise

Whatever definition of global health one uses, it always contains a normative element. To Koplan and colleagues, ${ }^{16}$ global health means "an area for study, research, and practice that places a priority on improving health and achieving equity in health for all people worldwide." For Beaglehole and Bonita, ${ }^{17}$ global health is "collaborative trans-national research and action for promoting health for all." Kickbush ${ }^{18}$ defines global health as "those health issues that transcend national boundaries and governments and call for actions on the global forces that determine the health of people." Global health's agents ought to improve health, ought to achieve equity in health, ought to promote health, or are called to take action. Who are global health's agents? Why should they do anything about global health? And why does it matter?

Normative conclusions can be derived from premises in a logically sound way, but they always require at least one normative premise - one that cannot be logically derived from empirical evidence alone. For example:

- If it is true (and empirically proven) that skilled birth attendance reduces maternal mortality

- And, if it is true that the international community ought to make all reasonable efforts to reduce maternal mortality worldwide

- Then it is logically true that the international community 
ought to make all reasonable efforts to increase skilled birth attendance worldwide.

This is a logically valid argument. The conclusion, however, requires both premises. And while the first premise can be empirically proven, the second cannot. If someone tells me that the international community has no responsibility whatsoever to reduce maternal mortality worldwide-and that only national governments have such a responsibility - I can argue that such a normative premise is contradictory to the millennium development goals (MDGs), contradictory to international human rights law, or contradictory to my own or someone else's ethical standards, but I will never be able to prove empirically that the premise is false.

Then why would someone, or some institution, take action to improve people's health in a foreign country? Many answers are possible. Out of compassion, perhaps-witnessing the plight of people living in less fortunate countries, people or institutions from more fortunate countries feel compelled to act. Enlightened self-interest is another possible answer. Watching epidemics unfold in other parts of the world, some people, or institutions, feel they should intervene to protect their interests. Justice-or, more narrowly, human rightscould be another reason: people or institutions feel or accept they have a legal obligation to realize a minimum level of the right to health abroad. One can probably think of other reasons for health agency abroad, but these three alternatives suffice to make my point. What matters is:

- $\quad$ Each of these 3 normative premises may lead to different policy options.

- None of these 3 normative premises can be empirically proven.

- None of these 3 normative premises has gathered sufficiently wide consensus to allow us to ignore the alternatives.

Allow me to use a concrete global health recommendation to illustrate my point. Denny and Emanuel ${ }^{19}$ argue that " $\left.\mathrm{t}\right] \mathrm{he}$ allocation of international health aid should be guided by 3 fundamental principles: (1) to save the most lives; (2) to save young lives in particular; and (3) to do so using finite resources most effectively", and therefore, they argue, that increasing international health aid spending on AIDS treatment "means that health needs unrelated to HIV/AIDS will remain unmet." There is obviously something missing in this argument. Even if AIDS treatment indeed costs "between $\$ 350$ to $\$ 2010$ per disability-adjusted life-year (DALY) averted," as Denny and Emanuel argue, it does not necessarily mean that other health needs will remain unmet. If, and only if, there is not enough money to address all health needs that are equally or more cost-effectively addressed, then, providing AIDS treatment means that cheaper-to-address health needs will remain unmet. Implicitly, Denny and Emanuel ${ }^{19}$ argue that there is not enough money to provide AIDS treatment and all equally or more cost-effective interventions. (Explicitly, they only argue that "[i]nternational aid is inherently limited," but there is a crucial difference between accepting that international health aid is limited and accepting that international health aid is limited at a point below the level required to include AIDS treatment.) Returning to the normative premises above: - If international health aid were based on the right to health, then it ought to be sufficient to help finance all essential healthcare, including AIDS treatment.

- If international health aid were based on enlightened selfinterest, then it should indeed be used chiefly to control infectious diseases (and include AIDS treatment).

- If international health aid were based on charity, then it should take into account the particular sensitivities of the 'donors' and their constituencies (and, again, probably include AIDS treatment).

It therefore appears as if Denny and Emanuel are applying a normative premise that is a mixture of international health aid as charity and public health utilitarianism; namely wealthier countries are free to decide how much aid they give, but whatever they give should be used to save as many lives as possible. AIDS advocates will take issue with this normative premise: they will argue that wealthier countries should give enough aid to avoid having to make the choice Denny and Emanuel propose. And, the American Congress may take issue with this normative premise, but in a different way: it may believe that saving American lives-through infectious disease control-is more important than saving non-Americans lives. Thus, the choice of normative premise will result in different policy preferences, even if the empirical evidence were unequivocal.

Thus, a substantial part of the "implementation gap between knowledge and action" in global health, ${ }^{20}$ could be explained by differences in normative premises, rather than differences related to the empirical evidence. The people producing the knowledge are using different normative premises than the people with the power to steer the response. If we do not include the normative differences in the debate, we will continue to run around in circles, wondering why global health's policy-makers are not implementing the knowledge generated by global health's empirical scholars.

\section{Stealth Advocacy and Unconscious Dogmatism}

As mentioned above, many global health scholars are reluctant to engage in the normative debate because it reeks of advocacy. Further, it requires taking positions that cannot be empirically proven, and that may take us down the path to policy recommendations "driven by crises, hot issues, and the concerns of organized interest groups,"15 the path we are trying to move away from.

To be clear, I do not agree that advocacy is problematic. By advocacy, I mean "the act or process of supporting a cause or proposal," as defined by the Merriam-Webster online dictionary. I find it rather difficult to imagine meaningful global health research that is not supporting a cause or proposal-global health is a cause. I do have problems with stealth advocacy, and by stealth advocacy I mean advocacy disguised as the outcome of a logical process that relied entirely on empirical evidence, and thus fails to acknowledge the underlying normative premise. Stealth advocacy is problematic for 5 key reasons. First, it is misleading, as it inevitably includes a normative premise somewhere, but that normative premise is probably buried under thick layers of empirical evidence. Second, it makes debate with scholars who use a different normative premise impossible. Third, it may lead to unrealistic policy proposals, because the policy- 
makers' normative premise may differ from that of the researcher. Fourth, by implying that empirical evidence is all that matters, it fails to 'speak to power' and thus covers up the role of politics and power in global health. And that leads to the most problematic consequence of stealth advocacy: the role of the powerhouses of global health remains unchallenged because the true scope of their influence is downplayed or ignored.

Some global health scholars do not practice stealth advocacy when they propose policy without highlighting their normative premise: they simply assume that their own normative premise is self-evident, and shared by all involved in the debate. Again, let me clarify that I do not think that dogmatism is always problematic. Dogmatic, according to the Merriam-Webster online dictionary, means "expressing personal opinions or beliefs as if they are certainly correct and cannot be doubted." Dogmatism can be very useful: if we had to start every paper by explaining that we believe surviving is better than dying, and that living a life with dignity is better than merely surviving, our papers would become very long and boring. So, there are personal opinions or beliefs that cannot be empirically proven, but that are nonetheless sufficiently widely shared to allow us to use them implicitly. But dogmatism based on opinions that are not unanimous (or almost unanimous) creates confusion. For example, if one scholar challenges the abolition of user fees for health services in low-income countries as unsustainable, using domestic financial self-reliance as the main criterion for sustainability, based on his or her personal opinion that countries ought to be financially self-sufficient, while another scholar understands sustainability as a capacity to endure over time, in combination with a personal opinion that open-ended international co-financing is entirely appropriate, they will never reach a form of understanding, unless they are willing to understand and acknowledge that their normative premise's differ. Like stealth advocacy, unconscious dogmatism covers up the role of politics and power in global health.

\section{Growing Pains}

Can we avoid the 'Scylla and Charybdis' - the stealth advocacy and the unconscious dogmatism - of global health? Not if we fail to acknowledge that a purely empirical evidencebased approach is a fiction. Using Lee's words, as long as global health scholars perceive the exercise of power and its underlying normative premises "in disparaging terms as a factor to be minimized or excluded," 10 they will continue to practice stealth advocacy or unconscious dogmatism. The first prerequisite for moving away from these practices is to acknowledge that no meaningful statement about health action abroad can be made without at least one normative premise - one that cannot be logically derived from empirical evidence alone, and one for which, at present, there is no broad consensus. The second prerequisite is to acknowledge that the humanities and social sciences, like international law, ethics, philosophy, and political science, are probably better equipped to study, analyze and discuss normative premises than biomedical sciences - and that a permanent and deeper interdisciplinary dialogue is needed. ${ }^{21}$ The third prerequisite is to value equally the input of biomedical and humanities and social science research, while understanding their different roles and limitations. Even if the law and social sciences may produce knowledge that is more influenced by (acknowledged) personal opinion and that is less readily replicated than the knowledge produced by biomedical sciences, ${ }^{22}$ the humanities and social sciences produce the best available answers to many questions that are essential for global health.

According to Grépin, ${ }^{13}$ "global health is usually more inclusive of social sciences than public health or international health; it is more multi-disciplinary and inter-disciplinary in nature." She may be right, but only in a relative, 'glass half full' sense: as long as the biomedical approach dominates the scholarly global health scene, ${ }^{10}$ global health's unproductive growing pains will continue.

Ethical issues

Not applicable.

Competing interests

Author declares that he has no competing interests.

Author's contribution

$\mathrm{GO}$ is the single author of the manuscript.

References

1. Bruen C, Brugha R. A ghost in the machine? Politics in global health policy. Int $J$ Health Policy Manag. 2014;3(1):1-4. doi:10.15171/ijhpm.2014.59

2. Kevany S. Global health diplomacy: a 'Deus ex Machina' for international development and relations; Comment on "A ghost in the machine? Politics in global health policy". Int $J$ Health Policy Manag. 2014;3(2):111-112. doi:10.15171/ijhpm.2014.67

3. Harmer A. Democracy - the real 'ghost' in the machine of global health policy; Comment on "A ghost in the machine? Politics in global health policy". Int J Health Policy Manag. 2014;3(3):149150. doi:10.15171/ijhpm.2014.75

4. McCoy D, Singh G. A spanner in the works? anti-politics in global health policy; Comment on "A ghost in the machine? Politics in global health policy”. Int J Health Policy Manag. 2014;3(3):151153. doi:10.15171/ijhpm.2014.77

5. Brugha R, Bruen C. Politics matters: A response to recent commentaries. Int J Health Policy Manag. 2014;3(3):157-158. doi:10.15171/ijhpm.2014.80

6. Shiffman J. Knowledge, moral claims and the exercise of power in global health. Int J Health Policy Manag. 2014;3(6):297-299. doi:10.15171/ijhpm.2014.120

7. Brown GW. Knowledge, politics and power in global health; Comment on "Knowledge, moral claims and the exercise of power in global health". Int J Health Policy Manag. 2014; 4(2):111-113. doi:10.15171/ijhpm.2015.20

8. Engebretsen E, Heggen K. Powerful concepts in global health; Comment on "Knowledge, moral claims and the exercise of power in global health". Int J Health Policy Manag. 2014; 4(2):115-117. doi:10.15171/ijhpm.2015.19

9. Hanefeld J, Walt G. Knowledge and networks - key sources of power in global health; Comment on "Knowledge, moral claims and the exercise of power in global health". Int $J$ Health Policy Manag. 2014;4(2):119-121. doi:10.15171/ijhpm.2015.25

10. Lee K. Revealing power in truth; Comment on "Knowledge, moral claims and the exercise of power in global health". Int $\mathrm{J}$ Health Policy Manag. 2014;4(4):257-259. doi:10.15171/ijhpm.2015.42

11. Rushton $\mathrm{S}$. The politics of researching global health politics: 
Comment on "Knowledge, moral claims and the exercise of power in global health". Int J Health Policy Manag. 2015; 4(5):311-314. doi:10.15171/ijhpm.2015.42

12. Levine RE. Power in global health agenda-setting: The role of private funding; Comment on "Knowledge, moral claims and the exercise of power in global health". Int J Health Policy Manag. 2015;4(5):315-317. doi:10.15171/ijhpm.2015.51

13. Grépin KA. Power and priorities: the growing pains of global health: Comment on "Knowledge, moral claims and the exercise of power in global health". Int $\mathrm{J}$ Health Policy Manag. 2015;4(5):321-322. doi:10.15171/ijhpm.2015.48

14. Yamey G, Feachem R. Evidence-based policymaking in global health - the payoffs and pitfalls. Evid Based Med 2011;16(4):9799. doi:10.1136/ebm.2011.100060

15. Committee for the Study of the Future of Public Health, Division of Health Care Services, Institute of Medicine. The Future of Public Health. Washington, DC: National Academies Press; 1988.

16. Koplan JP, Bond TC, Merson MH, et al. Towards a common definition of global health. Lancet 2009;373(9679):1993-1995. doi:10.1016/s0140-6736(09)60332-9

17. Beaglehole R, Bonita R. What is Global Health? Glob Health Action. 2010;3:5142.

18. Kickbush I. The need for a European strategy on global health. Scand J Public Health. 2006;34(6):561-565. doi:10.1080/14034940600973059

19. Denny C, Emanuel E. US health aid beyond PEPFAR: The mother \& child campaign. JAMA 2008;300(17):2048-2051. doi:10.1001/jama.2008.556

20. Haines A, Kuruvilla S, Borchert M. Bridging the implementation gap between knowledge and action for health. Bull World Health Organ. 2004;82(10):724-732.

21. Ooms G. From international health to global health: how to foster a better dialogue between empirical and normative disciplines. BMC International Health and Human Rights. 2014;14:36. doi:10.1186/s12914-014-0036-5

22. Kagan J. The Three Cultures: Natural Sciences, Social Sciences and the Humanities in the 21st Century. Cambridge: Cambridge University Press; 2009. 